\title{
Product Upgradability: Towards a Medical Analogy
}

Yannick Chapuis ${ }^{\star}$, Frédéric Demoly, Eric Coatanéa, and Samuel Gomes

\author{
IRTES-M3M, \\ Université de Technologie de Belfort-Montbéliard (UTBM), \\ 90010 Belfort Cedex, France \\ \{yannick. chapuis, frederic.demoly, samuel.gomes\}@utbm.fr, \\ eric.coatanea@aalto.fi
}

\begin{abstract}
This paper explored the analogy between the medical area and product design. Many similarities, shared between the genetic mutation permitting human to ensure its survival and the product undergoing the introduction of new technologies to meet the market fluctuation, are found to propose this analogy. From creating genetic reference space to transplant technology into product, fundamental process of survival and evolution will be described and allows the parallel with a product, to understand how the evolution of product respond to future needs. It also ensures the durability of resources in an ecological perspective. We discuss the complexity of establishing the right diagnosis for directing the design to choose the right technology and to enable its future integration into a living product. This uncertainty in the technological maturity but also the integrability of this technology in the current product at first, then in the future will allow its product development. Conclusions for the use of this analogy and the justification to describe "living product" will be drawn.
\end{abstract}

Keywords: Upgradability, DFX, Living product, Changeable product, Technology introduction, Proactive engineering.

\section{Introduction}

Nowadays, products with a long life span such as airplanes, oil rigs, diggers or centrals power generation need to be progressive, scalable and/or upgradable. As well, this products type are increasingly complex mostly in the area of high value-added products. More generally, these products are more complex due to successive and concatenation of innovations introduction while product constraints need a capitalization of all developed technologies. This faculty belongs to the design phase but more and more in the post design phase, with different maintenance laps time, updates, and duration of utilization need to be explored. When the product is designed, mature technologies are introduced to ensure a best performance and attractive product, but, with this large time scale, it

\footnotetext{
* Corresponding author.
} 
is more and more important to take into account the future. Today, the consumer society encourages people to consume even more, and in a lapse of time shorter and shorter. Sometimes, minimal changes in consumer behavior lead to modifications in the product use. This is the paradigm of the 21st century as the company tries not to consume more resources to ensure the sustainability of resources for the next generations. Therefore, to mix the two issues that are totally different, it is necessary to make more "alive", scalable products, and to make products in time. They must be able to withstand genetic mutations, technological transplants, but also to integrate the technological future years to come based on what is known at the present time. That is why we propose in this paper a medical analogy to our live product to fit best with the needs of the market while minimizing the total redesign of product.

\section{Background and Positioning}

\subsection{Global Positioning}

Nowadays, researchers efforts are focused on three mains parts. Some of them are concerned by getting ownership on past and present design intents [6] (left loop), some others work on the best way to use capitalized knowledge to reuse into product 14. (connection between the two loops). This paper evolve on future predictions to predict potential evolution of the product to ensure his upgradability with new technologies. As shown in the Fig. 1 mains steps included in the right loop are (1), (2), (3), and (4). This positioning deals with predictions of future evolution and/or introduction technologies [3] [4, evaluation of scenarios

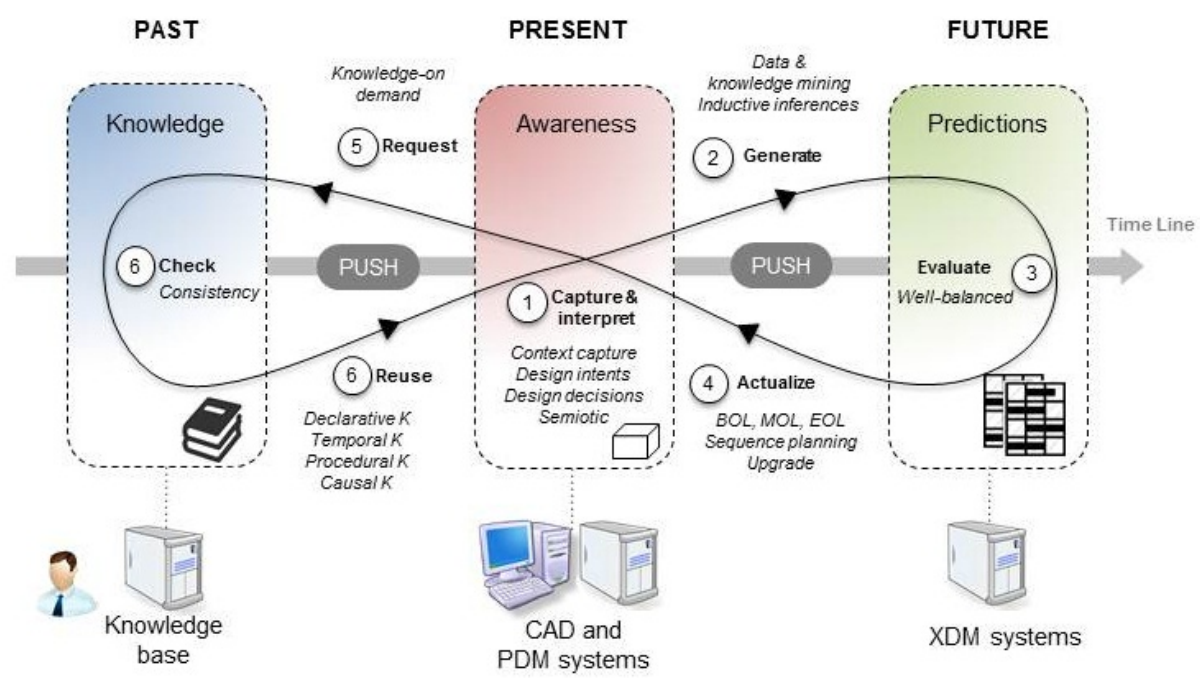

Fig. 1. Current research approaches 
maturity level and integrability of news technologies and permit present product to enhance with potential mutation during its life. That's why we propose the notion of "living products" to present its capability to change his architecture throughout its life.

\subsection{Developed and Ongoing Methods and Tools}

The last decade has seen many DFX grow to meet different issues [7]. The DFX for Design For $\mathrm{X}$, where $\mathrm{X}$ target a part of product lifecycle, is a methodology to take into account some constraints to be be proactive in the design phase. we can note two mains DFX and one specific DFX call DTX Design To X where X represent a specific parameter of the design in the middle of life of the product. So, we can resume this global philosophy on the Fig. 2.

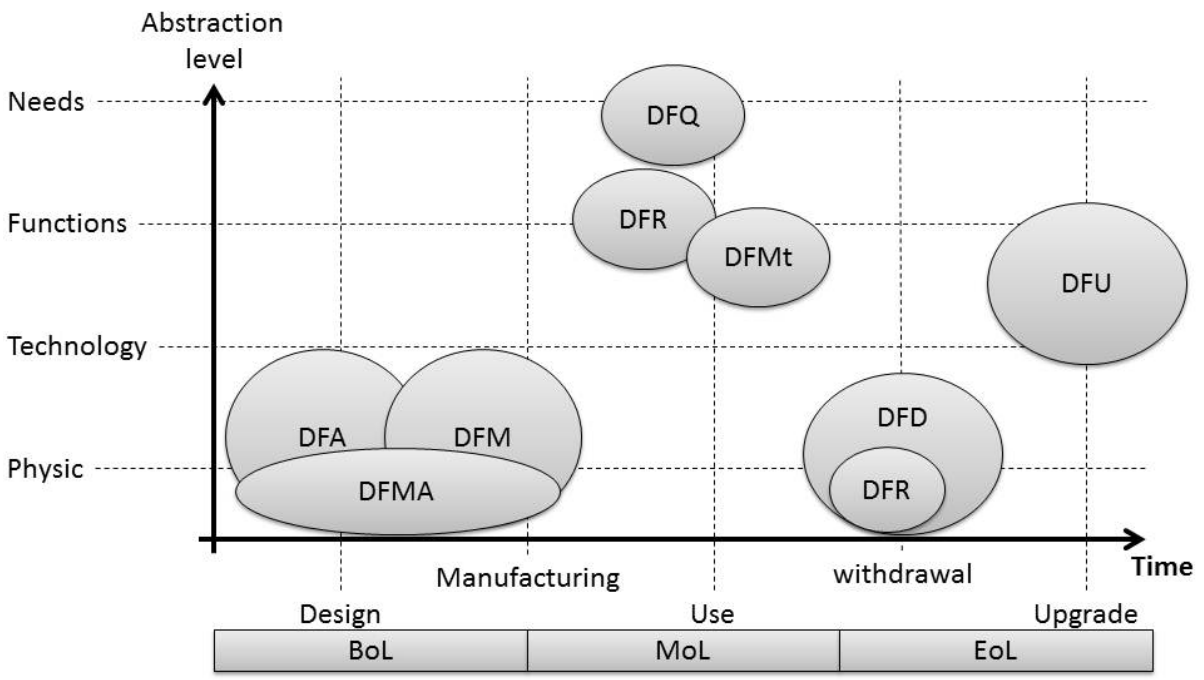

Fig. 2. Philosophy of DFX and DTX on product life cycle

Here, authors have represent some mains example of DFX in the Beginning of Life (BoL) of the product like Design For Manufacturing 2, Design for Assembly [5] and both [1] [16. The End of Life (EoL) of the product is more focused on Design for dis-assembly [8] or Design for Recycling [11. Mains parameters targeting for DTX in Middle of Life (MoL) are Quality [9], Reliability [12, Maintainability [15] or performance of the product. Only one virtue DFX impacted 
all the life cycle of the product, is the Design For Environmental friendly [10] [13, which impact form use of the natural resources, the less consumption, and for it impact less when it is withdrawing. Authors propose to take into account all aspects of the design of a product, from need to physic architecture. As shown in (Fig. 2), the Design for Upgradablity is posted at the end of product life cycle and consider needs, functional architecture, technologies and concept, physic architecture. The analogy of genetic mutation is used to prepare present to integrate a potential future, and allow to be proactive in the development of evolution scenarios of product technology and exhibit the need of product to be upgradable.

\subsection{Industrial and Market Challenges}

Nowadays, logical consumption involve on product design, but, today's industry need to impose their product with the faculty on to be proactive on predictive scenario of evolution of their product to drive customers to their solution.

\section{Vocabulary and Mutation Analogy}

\subsection{Genetic Code}

The genetic mutation is based on a common reference for each individual, i.e. the genetic code, the DNA (DeoxyriboNucleic Acid). DNA is considered as a chemical carrier of genetic information (possibility to enter the nucleotide sequence that characterizes each chromosome). It is necessary to build an information card to elaborate a map using the data present in a PDM (Product Data Management), a set of concatenation information. This informational card must contains information relating to RFLP model, namely, Requirement, Functional, Logical and Physic. The routing from data to knowledge via information is through the understanding context. Information is a data that have a meaning where an interpretation was given. Information allows an operational manager to make a decision (local or global scale) on action to be taken. Knowledge is the result of a reflection on the information analyzed, based on their experiences, ideas, values, opinions or on its own expertise and those of its peers. Each DNA strand includes a sequence of nucleotides, which are themselves composed of nitrogenous bases, monosaccharides (deoxyribose) and phosphate groups. There are four different nucleotides in the DNA, denoted A, G, C and T, the name of the corresponding bases. These nucleotides are grouped by special pairs:

- A with T

$-\mathrm{T}$ with $\mathrm{A}$

- C with G

- G with $\mathrm{C}$ 


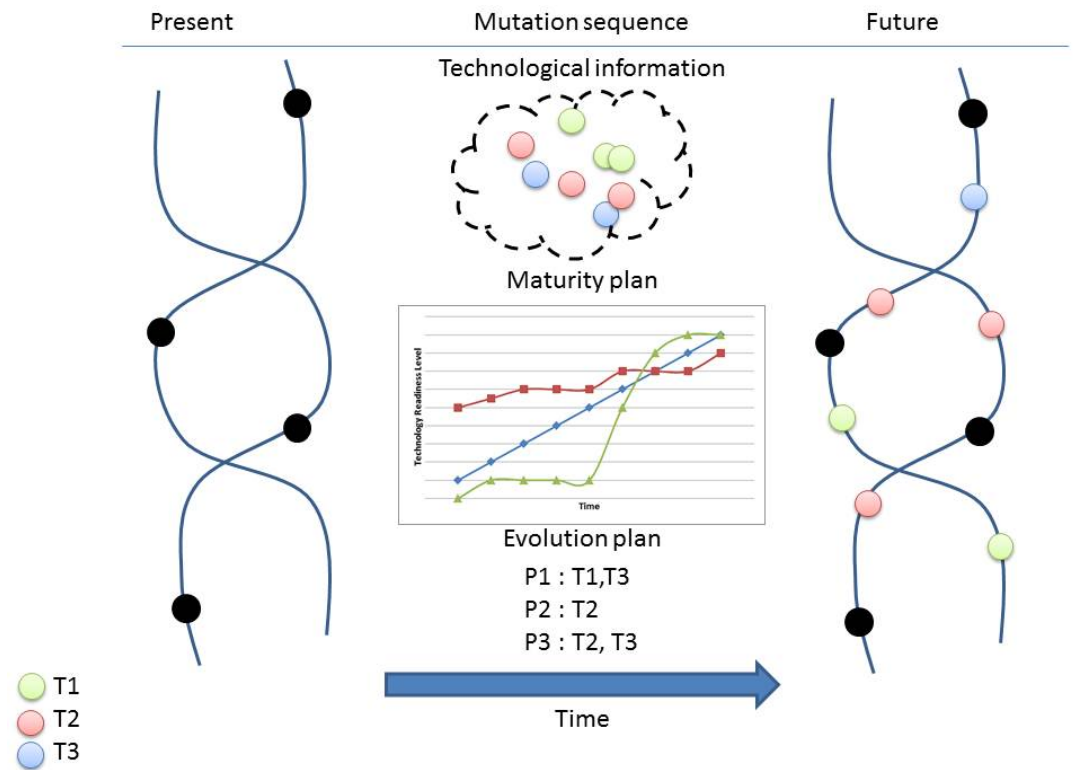

Fig. 3. Genetic code

These types of pairs correspond with the sequential logic design, namely, the need with requirements and functions with the organ. That is why, in a fixed context, we are in measure to validate the requirements with the needs and to propose functional and organic architecture to meet their needs. Here, in the context of product design, we will add a dependency between $\mathrm{A}$ and $\mathrm{C}$ (and conversely between $\mathrm{C}$ and $\mathrm{A}$ ) because it is obvious that the function must fulfill the requirements. Any change in the nucleotide sequence is a mutation. As in the product, when the need and the solution proposed are not linked, we need a genetic mutation. So, if you link market with the $\mathrm{A}$ and $\mathrm{T}$ and the solution with $\mathrm{C}$ and $\mathrm{G}$, when a change happens in one of this two area, a mutation is required.

\section{2 mutagen Factor}

The mutation in evolution is paramount, it is the only source of new genes. Adapting to a new situation requires a certain level of genetic variation to provide a mutation. The origins of a mutation called mutagenic or mutagen factor, can be physical or chemical. So the new situation mutagen may as well come from the inside and outside of the product. Indeed, a reversing caused by a distortion between the product and the customer creates a new situation to define the introduction of new technology in the product. That's why customer could not be prepared to this evolution. As already said, the market with impact on $\mathrm{A}$ and $\mathrm{T}$ sequence is an outside mutation. When there is changes in consumer 
habits, namely a new application for a product or service, manufacturers are often forced to respond with a new product which guarantees the sustainability of the company. However, in anticipation of these developments, it should be possible to change only part of the product because there is rarely a sudden change in the basic product. But it is possible that the change comes from industry itself through the introduction of new technology or by adding a new feature. At this time, it is a mutation affecting the sequences $\mathrm{C}$ and $\mathrm{G}$ and an internal transfer mastered by the company. This mutation can have a strong impact on consumption patterns and also on another product.

\section{Process and Fitness}

\subsection{Diagnosis}

The diagnosis is still based on a state that is generally accepted by all and represents the reference state. In the field of genetic mutation, this reference is called the karyotype. Karyotype is the standard arrangement of all chromosomes of a cell taken from a microscopic view. Chromosomes are photographed and arranged in a standard format by pair, classified by size and by the centromere position. The karyotype was performed in order to detect chromosomal aberrations (such as trisomy 21) or to identify several aspects of the human genome, such as sex (XX or XY). Note that a karyotype is in the form of photography. Etiology is the study of causes and factors of disease, etiology defines the origin of a disease based on semiotic events (Medical semiology is part of medicine that studies symptoms, signs and how to identify and present it in a diagnosis). Be careful sophistry, a cause does not necessarily correspond to the same effect, and vice versa, this is where the justification for the use of some Bayesian network for research and effect analysis. For medical diagnosis, two examinations could be done:

- Clinic, for physical examination, in this case, presence of two dichotomies:

- The first information is about the general signs (temperature, fatigue ...) and focal signs (delimits a zone ...)

- The second is about functional information signs (pain that is not verifiable) and physical signs (redness, noise ...).

- Para-clinical and then for additional radios, scanner, blood test...

\subsection{Mutation}

Product mutation is triggered after a gap between past and present or present and future. Currently, automobile manufacturers recall many vehicles which don't reach past needs comparing with vehicles currently produced. In the medical field, mutations are classified according to their consequences (phenotypic), that's why we can take again cases to organize them depending on mutation reason, curative or proactive. In this field, genetic mutation is seen as an alteration of the genetic information in a cell or virus genome. So as soon as there 
is a change of the solution or the need, we are in the presence of a mutation. A genetic mutation is called hereditary if the mutation forms a new organism, it may will an evolution of the species, this implies that it is possible to make a non-inherited mutation in a fleet of product already sold, but to be hereditary it must impacted all products already marketed but also his definition in the design of future product. Dynamic mutation is a mutation evolving from one generation to another, this is the typical case for updates software or with each new release, a number of functionality of the old version's recovery, while preparing the future features, at least, allow their development. In general, the mutation seeks to increase the "fitness" long-term (chance of survival), as humans, the basis must be durable in time, to find there the more evolution possible. When there is change of design data following a genetic mutation (realignment of the solution with respect to the need), only one said germ cell allows the propagation of the mutation (fertilization). Therefore, depending on healing mutations, it is necessary to have a Feedback on design data reflecting the need to create new, or how the product responds again. So we can build a summary table of all cases of mutation and to extract paths mutation based on problem identification.

\subsection{Fitness or Fixing}

The fitness is the consequence of the mutation, i.e. an improvement of the product relative to need. this is generally the case when a new technology is introduced. The fixing matches upgrading the product relative to need is the case of repairs, or the level of need has not changed, but the product became obsolete relative to its expected level.

\section{Conclusions and Future Work}

In this paper, authors proposed a method to take into account the earlier as possible the technological introduction in product design with a life-cycle point of view. This consideration is necessary in order to achieve innovative process to improve the product and to be able to be more competitive. Finally, different issues needs furthers research as criterion of technologies resources, tree learning occurs through the technological knowledge, generation algorithm scenarios taking into account the maturity and technological integrability. And in the more distant future, architecture is able to learn all technological links with associated system in the product and vision board quantitative change of entry criteria in relation to overall suitability.

Acknowledgments. The research activity is part of the INGéPROD (Productiveness for Product-Process Engineering in a Design Chain context), which has been funded by French Automotive Cluster Pôle de Compétitivité Véhicule du Futur. The authors would like to thank General Electric for this collaboration and all the financial supports of this research and technology program: DRIRE de Franche-Comté, Communauté dAgglomération du Pays de Montbéliard, Conseil Général du Doubs and Conseil Régional de Franche-Comté. 


\section{References}

1. Barnes, C.J., Jared, G.E.M., Swift, K.G.: Decision support for sequence generation in an assembly-oriented design environment. Robotics and Computer-Integrated Manufacturing 20, 289-300 (2004)

2. Bralla, J.: The design for manufacturability handbook, 2nd edn. McGraw-Hill, New York (1999)

3. Chapuis, Y., Demoly, F., Gomes, S.: Towards an approach to integrate technological evolution into product design. In: International Conference on Engineering Design (2013)

4. Chapuis, Y., Demoly, F., Gomes, S.: A novel framework for technological evolution within product architecture. In: Prabhu, V., Taisch, M., Kiritsis, D. (eds.) APMS 2013, Part I. IFIP AICT, vol. 414, pp. 219-226. Springer, Heidelberg (2013)

5. Edwards, K.L.: Towards more strategic product design for manufacture and assembly: priorities for concurrent engineering. Materials and Design 23, 651-656 (2002)

6. Gruhier, E., Demoly, F., Abboudi, S., Gomes, S.: A spatiotemporal mereotopology based theory for qualitative description in assembly design and sequence planning., United Kingdom, J.S. Gero. (2014)

7. Holt, R., Barnes, C.: Towards an integrated approach to Design for X: an agenda for decision-based DFX research. Research in Engineering Design 21(2), 123-136 (2010)

8. Kroll, E., Hanft, T.A.: Quantitative evaluation of product disassembly for recycling. Research in Engineering Design 10, 1-14 (1998)

9. Kuo, T.-C., Huang, S.H., Zhang, H.C.: Design for manufacture and design for: concepts, applications and perspectives. Computers and Industrial Engineering 41, 241-260 (2001)

10. Luttrop, C., Lagerstadt, J.: EcoDesign and the ten golden rules: generic advice for merging environmental aspects into product development. Journal of Cleaner Production 14, 1396-1408 (2006)

11. Masanet, E., Auer, R., Tsuda, D.: An assessment and prioritization of design for recycling guidelines for plastic components. In: IEEE International Symposium on Electronics and the Environment, pp. 5-10 (2002)

12. Minehane, S., Duane, R., O'Sullivan, P.: Design for reliability. Microelectronics Reliability 40, 1285-1294 (2000)

13. O'Shea, E.K.: Design for environment in conceptual product design a decision model to reflect environmental issues of all life-cycle phases. The Journal of Sustainable Product Design 2, 11-28 (2004)

14. Petrazoller, N., Demoly, F., Deniaud, S., Gomes, S.: Towards a knowledge-intensive framework for top-down design context definition. In: Prabhu, V., Taisch, M., Kiritsis, D. (eds.) APMS 2013, Part I. IFIP AICT, vol. 414, pp. 210-218. Springer, Heidelberg (2013)

15. Slavila, C.-A., Decreuse, C., Ferney, M.: Maintainability evaluation during the design phase. In: Proceedings of the IDMME 2004 Conference, Bath, UK, pp. 5-7 (2004)

16. Swift, K.G., Booker, J.D.: Process selection: from design to manufacture, 2nd edn. Butterworth-Heinemann, Oxford (2003) 